B. Katrincsakova, Z. Pikalova, P. Kurfurst, K. Indrak

\title{
COMPARISON OF NEW FLU-BU12-TG CONDITIONING WITH THE STANDARD BU-CY MYELOABLATIVE REGIMEN IN PATIENTS UNDERGOING ALLOGENEIC STEM CELL TRANSPLANTATION FOR ACUTE MYELOID LEUKEMIA
}

\author{
Ludek Raida ${ }^{a *}$, Pavel Tucek ${ }^{\mathrm{b}}$, Edgar Faber ${ }^{\mathrm{a}}$, Jana Vondrakova ${ }^{\mathrm{a}}$, Zuzana Rusinakova ${ }^{\mathrm{a}}$, \\ Iva Skoumalova ${ }^{\text {a }}$, Jaromir Hubacek ${ }^{a}$, Marie Jarosova ${ }^{a}$, Beata Katrincsakova ${ }^{a}$, \\ Zuzana Pikalova ${ }^{\mathrm{a}}$, Pavel Kurfurst ${ }^{\mathrm{c}}$, Karel Indrak ${ }^{\mathrm{a}}$
}

\author{
a Department of Hemato-Oncology, University Hospital Olomouc and Faculty of Medicine and Dentistry, Palacky University \\ Olomouc, Czech Republic \\ ${ }^{b}$ Department of Geoinformatics, Faculty of Science, Palacky University Olomouc \\ c Department of Foreign Languages, Faculty of Medicine and Dentistry, Palacky University Olomouc \\ E-mail: raida@fnol.cz
}

Received: March 18, 2011; Accepted: July 12, 2011; Available online: September 5, 2011

Key words: Acute myeloid leukemia/Allogeneic stem cell transplantation/Conditioning/Busulfan/Cyclophosphamide/ Fludarabine

Aims. This study compares the outcomes of patients with high-risk acute myeloid leukemia (AML) who underwent allogeneic stem cell transplantation (SCT) after conditioning combining busulfan ( $16 \mathrm{mg} / \mathrm{kg}$ orally) and cyclophosphamide (120 mg/kg intravenously) (BU-CY) with those allografted after administration of fludarabine $\left(150 \mathrm{mg} / \mathrm{m}^{2}\right.$ intravenously), busulfan (12 mg/kg orally) and thymoglobulin ( $6 \mathrm{mg} / \mathrm{kg}$ intravenously) (FLU-BU12-TG).

Material and methods. SCT after BU-CY and FLU-BU12-TG was performed in 21 and 10 AML patients. There were no significant differences between groups in number of patients treated in complete disease remission, gender, age, donors, CD34+, mononuclear cell (MNC) count in the graft and follow-up period. However, significantly more SCTs from unrelated ( $90 \%$ vs. $19 \%$; $\mathrm{p}=0.00018)$ and HLA-mismatched donors $(50 \%$ vs. $0 \% ; \mathrm{p}=0.0004)$ were performed in the FLU-BU12-TG group. The Cox proportional hazards model was used to assess the risk of post-transplant AML relapse and non-relapse mortality (NRM). The probability of post-transplant 2-year event-free survival (EFS) and overall survival (OS) were calculated using the Kaplan-Meier method.

Results. No significant differences were found between the FLU-BU12-TG and BU-CY groups in risk of AML relapse $(\mathrm{HR}=1.036 ; 95 \% \mathrm{CI}[0.102-10.47] ; \mathrm{p}=0.9)$, post-transplant NRM (HR=0.25; 95\% CI [0.031 - 1.96]; $\mathrm{p}=0.18)$, 2-year EFS ( $89 \%$ vs. $43 \%$; $p=0.19)$ or OS ( $79 \%$ vs. $57 \%$; $p=0.23$ ).

Conclusion. These pilot results demonstrate the efficacy of the new FLU-BU12-TG conditioning regimen in patients allografted for high-risk AML. This conditioning might become an alternative approach in patients at high risk of severe post-transplant complications after the standard BU-CY myeloablative regimen.

\section{INTRODUCTION}

The BU-CY chemotherapy regimen is one of the most frequent types of myeloablative conditioning used in allogeneic SCTs. Its high non-hematologic toxicity associated with significant NRM may be adjusted by augmented antileukemic effect with a lower relapse rate in selected AML patients (young ones with a low comorbidity index). The myeloablative "dose limit" of oral busulfan is considered to be $9 \mathrm{mg} / \mathrm{kg}$ of recipient body weight (b.w.) (ref. ${ }^{1}$ ). Thus, a busulfan dose of $16 \mathrm{mg} / \mathrm{kg}$ combined with cyclophosphamide (a total dose of $120 \mathrm{mg} / \mathrm{kg} \mathrm{b.w.)} \mathrm{in}$ BU-CY (ref. ${ }^{2}$ ) is necessary to eliminate and successfully control the AML clone? Myeloablation (including antileukemic effect) can be achieved with a busulfan dose of $12 \mathrm{mg} / \mathrm{kg}$ b.w. without the addition of cyclophosphamide associated with higher toxicity ${ }^{3}$. Essential immunoablative effects leading to the achievement of stable donor cell engraftment may be provided with fludarabine and thymoglobulin. Such a regimen (FLU-BU12-TG) might be less toxic despite the myeloablative dose of busulfan and considered as conditioning with reduced toxicity. There may be some arguments against the use of thymoglobulin due to a potential decrease in graft-versus-leukemia (GVL) reaction and a higher relapse risk $^{4}$. However, this risk could be avoided with less intensive post-transplant graft-versus-host disease (GVHD) prophylaxis using cyclosporine A (CSP-A) only and shortening the period of immunosuppression. Some experience with conditioning combining fludarabine, busulfan (a dose of $8 \mathrm{mg} / \mathrm{kg}$ b.w.) and thymoglobulin and using different intensity of posttransplant GVHD prophylaxis (CSP-A alone vs. CSP-A and mycophenolate mofetil) was published by Mohty et al. However, this study did not confirm any significant difference in the incidence of acute or chronic GVHD and overall survival in regard to the used prophylaxis ${ }^{5}$. 
The major aim of the study was to compare the outcome (the risk of relapse and NRM, the probability of EFS and OS) of patients allografted for high-risk AML after two different conditioning regimens, BU-CY and FLU-BU12-TG. The second point of analysis was to examine donor hematopoiesis engraftment, manifestation of non-hematologic toxicity and incidence of GVHD.

\section{PATIENTS AND METHODS}

Thirty-one patients diagnosed with high-risk AML ( 25 in complete remission of the disease before initiation of the conditioning regimen) underwent allogeneic SCT. Twenty-one were allografted after the BU-CY and 10 after the FLU-BU12-TG regimen.

\section{$B U-C Y$ conditioning}

Busulfan was administered orally $1 \mathrm{mg} / \mathrm{kg}$ b. w. $4 \mathrm{x}$ daily on days $-8,-7,-6$ and -5 . Cyclophosphamide was applied intravenously $60 \mathrm{mg} / \mathrm{kg}$ b.w. daily on days -3 and -2 . Prophylaxis of hemorrhagic cystitis was provided with mesna at a dose of $400 \mathrm{mg} / \mathrm{m}^{2}$ recipient body surface area (b. s. a.) administered intravenously $6 \mathrm{x}$ daily on days -3 and -2 . Administration was started along with the first infusion of cyclophosphamide. Graft infusion was administered on day 0 .

\section{FLU-BU12-TG conditioning}

Busulfan was administered orally at a dose of $1 \mathrm{mg} /$ $\mathrm{kg}$ b.w. four times daily on days $-8,-7$ and -6 . Fludarabine was applied intravenously at a dose of $30 \mathrm{mg} / \mathrm{m}^{2}$ b.s.a. daily on days $-6,-5,-4,-3$ and -2 . Thymoglobulin was administered intravenously at a dose of $1.5 \mathrm{mg} / \mathrm{kg}$ b.w. daily on days $-5,-4,-3$ and -2 by 12 -hour infusions preceded by premedication with intravenous methylprednisolone at a dose of $1 \mathrm{mg} / \mathrm{kg}$ b.w. and $1000 \mathrm{mg}$ of metamizole. Stem cells were transfused on day 0 .

\section{The source and number of transfused hematopoietic stem cells}

All but one patient in the BU-CY group (95\%) were allografted with peripheral blood stem cells (PBSCs). The recipients conditioned with BU-CY received the graft from HLA-matched related (MRDs) or unrelated (MUDs) donors in 17 (81\%) and $4(19 \%)$ cases, respectively. The median counts of transplanted mononuclear (MNCs) and CD34+ cells in that group were 7.7 (range $1.5-17.1$ ) x $10^{8} / \mathrm{kg}$ and 5.51 (range $1.54-9.32$ ) $\times 10^{6} / \mathrm{kg}$, respectively. After the FLU-BU12-TG conditioning, the bone marrow and peripheral blood were the sources of stem cells in $3(30 \%)$ and $7(70 \%)$ recipients, respectively. All but one recipient in this group (90\%) were allografted from unrelated donors. Stem cells were transplanted from MUDs and mismatched unrelated donors (MMUDs) in 4 $(40 \%)$ and $5(50 \%)$ cases, respectively. The median counts of MNCs and CD34+ cells in the graft were 7.18 (range $1.57-11.41$ ) x $10^{8} / \mathrm{kg}$ and 6.02 (range $\left.1.31-8.3\right) \times 10^{6} / \mathrm{kg}$, respectively.

\section{Post-transplant GVHD prophylaxis}

GVHD prophylaxis in patients treated with BU-CY was provided with CSP-A $(3 \mathrm{mg} / \mathrm{kg}$ b.i. d. on days -1 to +60 and then gradually tapered and stopped on day +180 ) combined either with short methotrexate (MTX) $\left(15 \mathrm{mg} / \mathrm{m}^{2}\right.$ on day +1 and $10 \mathrm{mg} / \mathrm{m}^{2}$ on days $+3,+6$ and $+11)$ in $8(38 \%)$ or MMF $(15 \mathrm{mg} / \mathrm{kg}$ b.i.d. on days +1 to +30 and then gradually tapered and stopped on day $+60)$ in $13(62 \%)$. Two immunosuppressive approaches to GVHD prophylaxis were used in recipients conditioned with FLU-BU12-TG as well. Five patients (50\%) transplanted from MRDs and MUDs received CSP-A only. The other five recipients (50\%) allografted after the same conditioning regimen but from MMUDs were treated with a prophylactic immunosuppressive combination of CSP-A and MMF.

\section{Infection prophylaxis}

The recipients were given co-trimoxazole at a dose of $960 \mathrm{mg} \mathrm{b}$. i. d. orally on days -8 to -1 . Since day 0 , cotrimoxazole was stopped until recovery of an absolute neutrophil count (ANC) $\geq 0.5 \times 10^{9} / 1$. Then it was started again at the same daily dose but administered on two days a week. The administration of co-trimoxazole was stopped 6 months after discontinuation of immunosuppressive drugs and if there was no evidence of GVHD. Prophylaxis of herpesvirus infections was provided with oral valacyclovir at a dose of $500 \mathrm{mg}$ b. i. d. or intravenous acyclovir at a dose of $250 \mathrm{mg}$ t.i.d. The herpes prophylaxis was started on day -8 and stopped 6 months after discontinuation of immunosuppression with regard to evidence of any form of GVHD. Fluconazole at a dose of $200 \mathrm{mg}$ a day orally or intravenously was given to the recipients from day -8 to recovery and stabilization of ANC $\geq 1.0 \times 10^{9} / 1$. Patients with a history of proven or probable systemic fungal infection received secondary prophylaxis with voriconazole at a dose of $200 \mathrm{mg}$ a day or posaconazole at a dose of 200 $\mathrm{mg}$ t.i.d. Selective gastrointestinal decontamination was performed with rifaximin $400 \mathrm{mg}$ b.i.d. from day -8 to stabilization of ANC $\geq 0.5 \times 10^{9} / 1$ and complete resolution of mucositis.

Cytomegalovirus (CMV) seronegative recipients allografted from CMV-seronegative donors were transfused with leukodepleted blood products (erythrocytes and platelets) containing less than $1.0 \times 10^{6}$ leukocytes per transfusion unit (TU). Regular screening of CMV-DNA in plasma was performed weekly until day +100 (if there had not been any evidence of acute or chronic GVHD and the need of corticosteroid or intensive immunosuppressive treatment) to avoid the development of CMV infection and disease.

\section{Non-hematologic toxicity}

The WHO scale was used to assess post-transplant non-hematologic toxicity in both conditioning groups.

\section{Hematologic recovery and engraftment}

Post-transplant hematologic recovery was assessed regarding increase and stabilization of ANC $\geq 0.5 \times 10^{9} / 1$ and platelets (PLTs) $\geq 20 \times 10^{9} / 1$ in the recipient's periph- 
eral blood. Chimeric status was evaluated in nuclear cells of peripheral blood and bone marrow aspirate on days $+15,+60,+270$ and $+30,+90,+180,+360$, respectively. Fluorescent short tandem repeat (STR) polymerase chain reaction (PCR) followed by capillary electrophoresis was used for this purpose. Peripheral blood samples were collected from the donor and recipient before SCT to establish a pre-transplant STR profile for each donor-recipient pair. These profiles were applied in the post-transplant period when donor chimerism was calculated as described by Nollet et al. ${ }^{6}$ The recipient was considered to achieve complete donor chimerism if $100 \%$ of peripheral blood or bone marrow cells were of donor origin.

\section{GVHD assessment}

The diagnosis of acute or chronic GVHD was made in regard to clinical manifestations and histological findings of biopsied tissue. GVHD was graded and staged according to the standard criteria $^{7-8}$.

\section{Statistical analysis}

The methods of univariate analysis were used to compare the basic data.. Normative data (recipient and donor age, number of transfused MNCs and CD34+ cells, hematologic recovery, post-transplant follow-up period) were analyzed using the parametric t-test. The analysis of non-normative/categorical data (recipient and donor gender, complete remission of AML at SCT, allografting from unrelated donors, HLA compatibility, non-hematologic toxicity grade, complete donor chimerism achievement on days +30 and +100 , development of acute and chronic GVHD, post-transplant AML relapse, NRM and overall mortality) was performed with the non parametric chi-squared test. The cumulative incidence rates of posttransplant AML relapse and NRM in both conditioning groups were compared by multivariate analysis using the Cox proportional hazards regression model ${ }^{9}$. The KaplanMeier method was applied to calculate the probability of EFS and OS (ref. ${ }^{10}$ ).

\section{RESULTS}

There were no significant differences between the two groups in the majority of basic parameters (recipient/donor gender and age, complete remission of AML at SCT, number of transfused MNCs and CD34+ cells, post-transplant follow-up period). On the other hand, the number of recipients allografted from unrelated and HLA-mismatched donors was significantly higher in the FLU-BU12-TG group (Table 1).

No significant differences were found in the incidence and grade of mucositis (stomatitis, gastroenteritis). Observed liver, renal, pulmonary and skin toxicity was not statistically compared because of relatively low incidence (Table 2). Clinical manifestations of liver toxicity were observed in only 5 patients (24\%) allografted after the BU-CY regimen. Liver toxicity did not exceed grade II and its manifestation correlated with the clinical criteria of mild veno-occlusive disease (VOD).

Hematological recovery and engraftment of donor hematopoiesis were achieved in all patients allografted after BU-CY and FLU-BU12-TG. There was no statistically significant difference between the groups in stabilization of $\mathrm{ANC} \geq 0.5 \times 10^{9} / 1$ and PLT $\geq 20 \times 10^{9} / 1$ after SCT.. There was no observed graft failure or rejection. No statistically significant differences in the achievement of complete donor chimerism on days +30 and +100 were found.(Table 3).

Development of acute GVHD was observed after BUCY and FLU-BU12-TG in 8 (38\%) and 5 (50\%) patients, respectively ( $p=0.53)$. Chronic GVHD was diagnosed in 8 of 18 evaluable patients (44\%) allografted after BU-CY and in 3 of 9 patients (33\%) treated with FLU-BU12TG ( $p=0.58)$. An extensive form of chronic GVHD was only observed in 4 recipients (22\%) treated with BU-CY. However, no statistical comparison was made because of the small number of patients.

Complete remission (CR) of AML was confirmed in all but one of 31 allografted patients on day +30 after

Table 1. The differences in baseline transplant parameters regarding to used conditioning.

\begin{tabular}{|l|c|c|l|}
\hline Parameter & BU-CY $(\mathrm{n}=21)$ & FLU-BU12-TG $(\mathrm{n}=10)$ & P-value \\
\hline Recipients age (median) & $40(20-55)$ years & $51(22-57)$ years & 0.09 \\
\hline Donors age (median) & $36(20-60)$ years & $36(22-49)$ years & 0.79 \\
\hline CR of AML at SCT & $18(86 \%)$ & $7(70 \%)$ & 0.3 \\
\hline Recipient-male / donor-female & $6(29 \%)$ & $2(20 \%)$ & 0.61 \\
\hline Unrelated donor & $4(19 \%)$ & $9(90 \%)$ & 0.00018 \\
\hline HLA matched donor & $21(100 \%)$ & $5(50 \%)$ & 0.0004 \\
\hline MNC in the graft (median) & $7.69(1.5-17.1) \times 10^{8} / \mathrm{kg}$ & $7.17(1.57-11.41) \times 10^{8} / \mathrm{kg}$ & 0.29 \\
\hline CD34+ cells in the graft $($ median$)$ & $5.52(1.54-9.32) \times 10^{6} / \mathrm{kg}$ & $6.03(1.31-8.3) \times 10^{6} / \mathrm{kg}$ & 0.6 \\
\hline Follow-up period (median) & $392(65-1895)$ days & $340(91-788)$ days & 0.06 \\
\hline
\end{tabular}


Table 2. The differences in non-hematological toxicity regarding to used conditioning.

\begin{tabular}{|c|c|c|c|}
\hline Non-hematological toxicity & BU-CY $(n=21)$ & FLU-BU12-TG $(\mathrm{n}=10)$ & P-value \\
\hline $\begin{array}{l}\text { Gastroenteritis } \\
\text { Grade I } \\
\text { Grade II } \\
\text { Grade III } \\
\text { Grade IV }\end{array}$ & $\begin{array}{c}21(100 \%) \\
2(10 \%) \\
11(52 \%) \\
7(33 \%) \\
1(5 \%)\end{array}$ & $\begin{array}{c}10(100 \%) \\
2(20 \%) \\
4(40 \%) \\
3(30 \%) \\
1(10 \%)\end{array}$ & 0.78 \\
\hline $\begin{array}{l}\text { Stomatitis } \\
\text { Grade I } \\
\text { Grade II } \\
\text { Grade III } \\
\text { Grade IV }\end{array}$ & $\begin{array}{c}21(100 \%) \\
1(5 \%) \\
3(14 \%) \\
15(71 \%) \\
2(10 \%)\end{array}$ & $\begin{array}{c}10(100 \%) \\
2(20 \%) \\
0 \\
7(70 \%) \\
1(10 \%)\end{array}$ & 0.38 \\
\hline $\begin{array}{l}\text { Liver toxicity } \\
\text { Grade I } \\
\text { Grade II }\end{array}$ & $\begin{array}{l}5(24 \%) \\
2(10 \%) \\
3(14 \%)\end{array}$ & 0 & not analyzed \\
\hline $\begin{array}{l}\text { Renal toxicity } \\
\text { Grade I } \\
\text { Grade II }\end{array}$ & $\begin{array}{c}3(14 \%) \\
0 \\
3(14 \%)\end{array}$ & $\begin{array}{l}2(20 \%) \\
1(10 \%) \\
1(10 \%)\end{array}$ & not analyzed \\
\hline $\begin{array}{l}\text { Pulmonary toxicity } \\
\text { Grade III }\end{array}$ & $\begin{array}{l}1(5 \%) \\
1(5 \%)\end{array}$ & 0 & $\begin{array}{c}\text { not } \\
\text { analyzed }\end{array}$ \\
\hline $\begin{array}{l}\text { Skin toxicity } \\
\text { Grade I } \\
\text { Grade II }\end{array}$ & $\begin{array}{l}2(10 \%) \\
1(5 \%) \\
1(5 \%)\end{array}$ & 0 & not analyzed \\
\hline
\end{tabular}

Table 3. Engraftment and hematological recovery regarding to used conditioning.

\begin{tabular}{|l|c|c|c|}
\hline \multicolumn{1}{|c|}{ Parameter } & BU-CY & FLU-BU12-TG & P-value \\
\hline $\begin{array}{l}\text { ANC } \geq 0,5 \times 10^{9} / 1 \text { (median) } \\
\text { No of evaluated recipients }\end{array}$ & $\begin{array}{c}\text { day }+15(11-18) \\
21(100 \%)\end{array}$ & $\begin{array}{c}\text { day }+16(13-45) \\
10(100 \%)\end{array}$ & \multirow{2}{*}{0.16} \\
\hline PLT $\geq 20 \times 10^{9} / 1$ median) & day $+11(9-21)$ & day $+11(9-14)$ & 0.22 \\
No of evaluated recipients & $21(100 \%)$ & $10(100 \%)$ & 0.06 \\
\hline $100 \%$ donor chimerism on day +30 & $7(33 \%)$ & $7(70 \%)$ & \multirow{2}{*}{0.16} \\
No of evaluated recipients & $21(100 \%)$ & $10(100 \%)$ & \multirow{2}{*}{ not analyzed } \\
\hline $100 \%$ donor chimerism on day +100 & $10(63 \%)$ & $8(89 \%)$ & $9(90 \%)$ \\
No of evaluated recipients & $16(76 \%)$ & 0 & 0 \\
\hline Graft failure / rejection & 0 & &
\end{tabular}

SCT. The only patient who failed to achieve CR had been allografted with bone marrow from a MMUD (1 allelic mismatch on DRB1) after the FLU-BU12-TG conditioning. However, that patient had suffered from progression of AML with high proliferative activity (leukocytosis with a high proportion of leukemic blasts in peripheral blood) at SCT. Relapse of AML in the BU-CY and FLU-BU12TG groups occurred in $5(24 \%)$ and $1(11 \%)$ patient, respectively. That difference was not statistically significant $(p=0.43)$. No significant difference between both groups of patients was found in the cumulative incidence of relapse (HR 1.036; 95\% CI [0.1 - 10.47]; p=0.9) (Fig. 1).
Over the post-transplant follow-up period, NRM among the recipients treated with BU-CY and FLUBU12-TG was observed in $1(10 \%)$ and 7 (33\%) of them, respectively $(p=0.11)$. No difference in the cumulative incidence of NRM was confirmed by multivariate analysis (HR 1.036; 95\% CI [0.034 - 2.26]; $p=0.23$ ) (Fig. 2).

Estimated 2-year EFS rates in patients allografted after BU-CY and FLU-BU12-TG were $43 \%$ and $89 \%$, respectively ( $p=0.086$ ) (Fig. 3). The probability of 2-year OS in both conditioning groups was $57 \%$ and $79 \%$, respectively $(\mathrm{p}=0.23)$ (Fig. 4). 


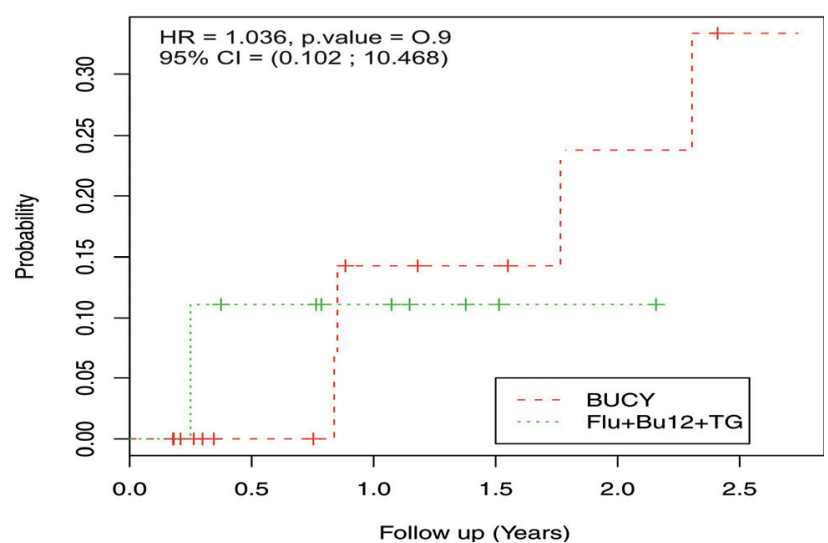

Fig. 1. The cumulative incidence of AML relapse regarding to used conditioning.

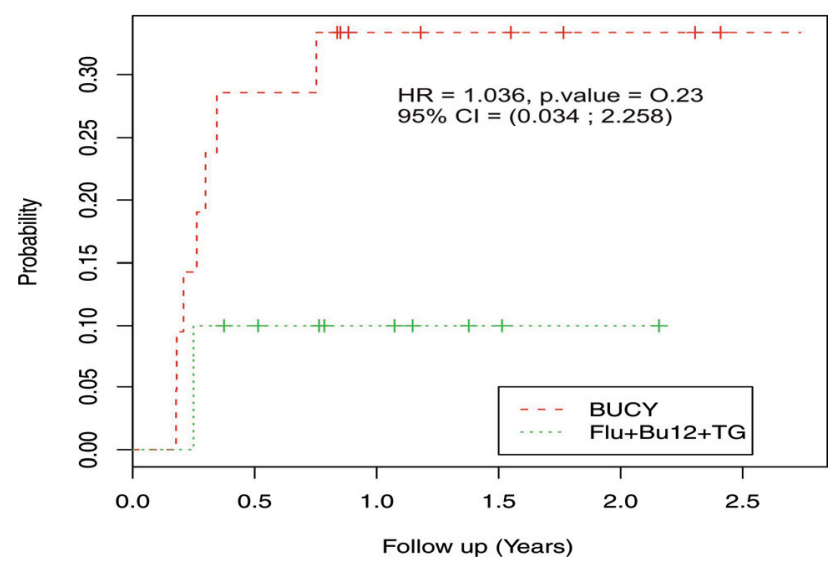

Fig. 2. The cumulative incidence of NRM regarding to used conditioning.

\section{DISCUSSION AND CONCLUSION}

The BU-CY myeloablative regimen is a standard conditioning used in patients undergoing allogeneic SCT for AML. However, its toxicity is high and it can be associated with higher post-transplant mortality. Non-myeloablative and reduced intensity conditioning (RIC) is less toxic and associated with lower NRM but the relapse rates are significantly higher, particularly in patients with AML (ref. $\left.{ }^{11-13}\right)$. Insufficient reduction of the leukemic clone may be the key reason and intensive GHVD prophylaxis can also lead to the loss of effective immunological antitumor control. A busulfan dose of $12 \mathrm{mg} / \mathrm{kg} \mathrm{b}$.w. without addition of cyclophosphamide should be myeloablative enough to allow stable donor cell engraftment and decrease the risk of AML relapse or progression.

The presented results confirm that allografting after FLU-BU12-TG conditioning was not associated with worse post-transplant hematologic recovery and achievement of $100 \%$ donor chimerism, higher risk of disease relapse or progression in AML patients despite a lower total dose of busulfan and "in vivo" $\mathrm{T}$ cell depletion provided by the use of thymoglobulin. Significantly higher SCTs from MUDs ( $40 \%$ vs. $19 \%$ ), MMUDs ( $50 \%$ vs. $0 \%$ ) and less intensive post-transplant GVHD prophylaxis with

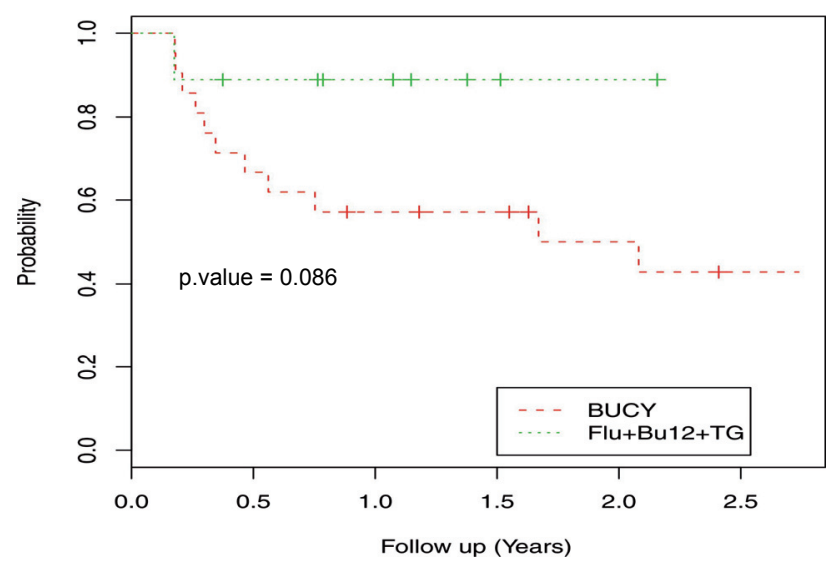

Fig. 3. The event-free survival probability regarding to used conditioning.

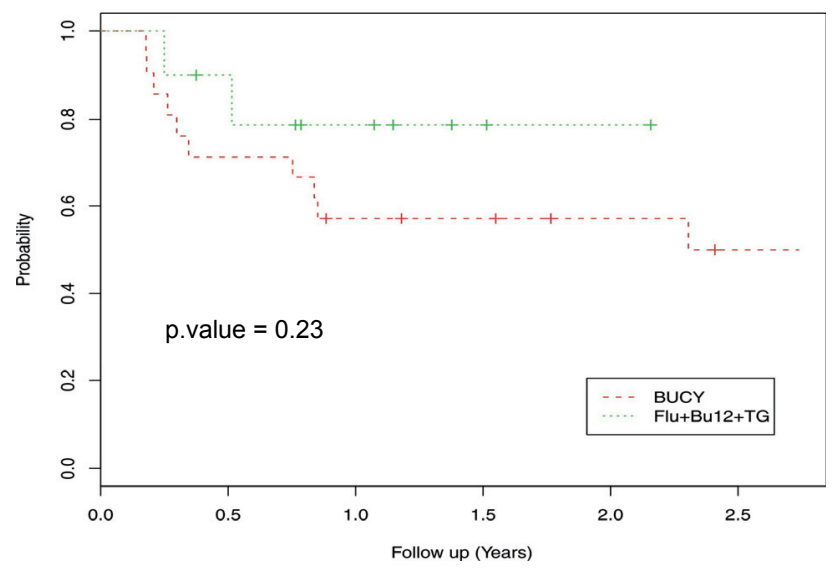

Fig. 4. The overall survival probability regarding to used conditioning.

CSP-A only could be the reasons for higher acute GVHD incidence ( $50 \%$ vs. $38 \%$ ) that might be associated with pronounced GVL reaction in the FLU-BU12-TG group. On the other hand, the development of chronic GVHD usually associated with lower relapse rates (better immunological control of leukemia as well) was slightly higher (not significantly) in the BU-CY group (44\% vs. 33\%).

Mucositis (stomatitis, gastroenteritis) was the most frequent manifestation of non-hematologic toxicity. There were no significant differences between the two compared conditioning groups in the incidence and severity of mucositis. Manifestations of mild VOD were observed only in the BU-CY group (24\% vs. 0\%). That observation showed the harmful influence of cyclophosphamide administered immediately after busulfan high doses on liver tissue. Statistical comparison of liver toxicity manifestation was not performed due to the small number of patients. The other forms of non-hematologic (renal, skin and pulmonary) toxicity were not statistically compared because of their rare incidence in both groups.

Despite comparable non-hematologic toxicity and acute GVHD incidence, there was higher cumulative incidence of NRM in the BU-CY group (33\% vs. 10\%). However, the difference between the groups was not statistically significant. The difference of $23 \%$ in the cumulative 
incidence of NRM in the horizon of two post-transplant years might be explained by higher chronic GVHD incidence including associated complications in the BU-CY group. Lower NRM and comparable relapse rate also resulted in better (but not significantly) overall survival in the FLU-BU12-TG group (79\% vs. 57\%).

To our knowledge, no study to date has compared BU-CY conditioning with the fludarabine-based regimen containing busulfan at a dose of $12 \mathrm{mg} / \mathrm{kg}$ (administered orally) or $9.6 \mathrm{mg} / \mathrm{kg} \mathrm{b.w.} \mathrm{(administered} \mathrm{intravenously).}$ The addition of thymoglobulin may intensify immunoablation allowing sustained engraftment of donor cells and also decrease the risk of early severe acute and maybe chronic GVHD. However, such "in vivo" T cell depletion may increase the risk of AML relapse or progression due to insufficient GVL reaction and it should be considered in further management of GVHD prophylaxis. Higher gastrointestinal toxicity of BU-CY associated with intensive local inflammation (mucositis), considered to be an "optimal” trigger of GVHD ( ref. $^{14}$ ), was not confirmed in that pilot study. The present analysis demonstrated the efficacy of the new FLU-BU12-TG conditioning regimen in patients allografted for AML. In spite of the limited numbers of patients, the outcome of those treated with FLU-BU12-TG was not worse than that in the BU-CY group. The myeloablative but non-hematologically less intensive conditioning regimen FLU-BU12-TG should be considered as an alternative approach in patients undergoing allogeneic SCT for AML but with a significant risk of severe post-transplant complications.

\section{ACKNOWLEDGEMENTS}

This work was supported by the grant MSM 6198959205 of the Czech Ministry of Education and the project LF-2011006 of Palacký University in Olomouc.

Disclosure: Authors declare no conflicts of interests.

\section{REFERENCES}

1. Bacigalupo A. Third EBMT/AMGEN Workshop on reduced-intensity conditioning allogeneic haematopoietic stem cell transplants (RIC-HSCT), and panel consensus. Bone marrow Transplant 2004;33:691-6.
2. Tutschka PJ, Copelan EA, Klein JP. Bone marrow transplantation for leukemia following a new busulfan and cyclophosphamide regimen. Blood 1987;70:1382-8.

3. Geller RB, Saral R, Piantadori S, Zahurak M, Vogelsang GB, Wingard JB, Ambinder RF, Beschorner WB, Braine HG, Burns WH, Hess AD, Jones RJ, May WS, Rowley SD, Wagner JE, Yeager $\mathrm{AM}$, and Santos GW. Allogeneic bone marrow transplantation after high-dose busulfan and cyclophosphamide in patients with acute nonlymphocytic leukemia. Blood 1989;73:2209-18.

4. Martino R, Caballero MD, Simon JAP, Canals C, Solano C, Urbano-Ispízua A, Bargay J, Léon A, Sarrá J, Sanz GF, Moraleda JM, Brunet S, San Miguel J and Sierra J. Evidence for graftversus-leukemia effect after allogeneic peripheral blood stem cell transplantation with reduced-intensity conditioning in acute myelogenous leukemia and myelodysplastic syndromes. Blood 2002;100:2243-5.

5. Mohty M, de Lavallade H, Faucher C, Bilger K, Vey N, Stoppa AM, Gravis G, Coso D, Viens P, Gastaut JA and Blaise D. Mycophenolate mofetil and cyclosporine for graft-versus-host disease prophylaxis following reduced intensity conditioning allogeneic stem cell transplantation. Bone Marrow Transplant 2004;34:527-30.

6. Nollet F, Billiet J, Selleslag D and Criel A. Standardisation of multiplex fluorescent short tandem repeat analysis for chimerism testing. Bone Marrow Transplant 2001; 28:511-18.

7. Przepiorka D, Weisdorf D, Martin P, Klingemann HG, Beatty P, Hows J, Thomas ED. 1994 Consensus Conference on Acute GVHD Grading. Bone Marrow Transplant 1995;15:825-8.

8. Sullivan KM, Agura E, Anasetti C, et al. Chronic graft-versus-host disease and other late complications of bone marrow transplantation. Semin Hematol 1991;28:250-9.

9. Cox D. Regression models and life tables. J R Stat Soc (B) 1972;34:187-220.

10. Kaplan E, Meier P. Nonparametric estimation from incomplete observations. J Am Stat Assoc 1957;53:457-81.

11. De Lima M, Anagnostoupolo A, Munsell M, Shahjahan M, Ueno N, Ippoliti C, Andersson BS, Gajewski J, Couriel D, Cortes J, Donato M, Neumann J, Champlin R, and Giralt S. Nonablative versus reduced-intensity conditioning regimens in the treatment of acute myeloid leukemia and high-risk myelodysplastic syndrome: dose is relevant for long-term disease control after allogeneic hematopoietic stem cell transplantation. Blood 2004;104:865-72.

12. Ringdén O, Labopin M, Ehninger G, Niederwieser D, Olsson R, Basara N, Finke J, Schredtfeger R, Eder M, Bunjes D, Gorin NC, Mohty M and Rocha V. Reduced intensity conditioning compared with myeloablative conditioning using unrelated donor transplants in patients with acute myeloid leukemia. J Clin Oncol 2009;27:4570-7.

13. Blaise D, Vey N, Faucher C, Mohty M. Current status of reduced intensity conditioning allogeneic stem cell transplantation for acute myeloid leukemia. Haematologica 2007;92:533-41.

14. Mielcarek M, Martin PJ, Leisenring W, Flowers MED, Maloney DG, Sandmaier BM, Maris MB and Storb R. Graft-versus-host disease after nonmyeloablative versus conventional hematopoietic stem cell transplantation. Blood 2003;102:756-62. 